\title{
Clinical Risk Profile for a Second Anterior Cruciate Ligament Injury in Female Soccer Players After Anterior Cruciate Ligament Reconstruction
}

Anne Fältström, Joanna Kvist, Natalia F. N. Bittencourt, Luciana D. Mendonca and Martin Hägglund

The self-archived postprint version of this journal article is available at Linköping University Institutional Repository (DiVA):

http://urn.kb.se/resolve?urn=urn:nbn:se:liu:diva-175989

N.B.: When citing this work, cite the original publication.

Fältström, A., Kvist, J., Bittencourt, N. F. N., Mendonca, L. D., Hägglund, M., (2021), Clinical Risk Profile for a Second Anterior Cruciate Ligament Injury in Female Soccer Players After Anterior Cruciate Ligament Reconstruction, American Journal of Sports Medicine, 49(6), 1421-1430.

https://doi.org/10.1177/0363546521999109

Original publication available at:

https://doi.org/10.1177/0363546521999109

Copyright: SAGE Publications

http://www.uk.sagepub.com/home.nav 


\section{Clinical Risk Profile for a Second Anterior Cruciate Ligament Injury in Female Soccer Players after Anterior Cruciate Ligament}

Reconstruction

Background: The risk of a second anterior cruciate ligament (ACL) injury when participating in pivoting sports after ACL reconstruction is high. Risk factors associated with a second ACL injury are complex.

Purpose: To investigate the combinations of various clinical risk factors associated with secondary ACL injury in female soccer players with a primary unilateral ACL reconstruction, using Classification and Regression Tree (CART) analysis.

Study Design: Cohort study.

Methods: A total of 117 active female soccer players (mean age \pm SD, $20 \pm 2$ years) were included. Athletes enrolled were $19 \pm 9$ months after ACL reconstruction and prospectively followed for 2 years. At baseline, all players underwent assessment of knee and ankle joint range of motion (ROM), functional tests (postural control, hop performance, and movement asymmetries in the lower limbs and trunk), and answered questionnaires (patient-reported knee function, knee-related quality of life, psychological and personality factors). A clinical prediction model utilizing CART was developed.

Results: Twenty-eight players (24\%) sustained a second ACL injury (21 ipsilateral and 7 contralateral ruptures) while playing soccer. CART analysis selected 9 of 19 independent variables associated with secondary ACL injury: the 5-jump test, knee collapse on the nonACL reconstructed leg in a drop vertical jump, tuck jump, Limb Symmetry Index on side hop and the single hop for distance, side difference in ankle dorsiflexion ROM, and scores for the questionnaires ACL-Return to Sport after Injury and the Swedish Universities Scales of 
Personality traits, stress susceptibility and adventure seeking. The accuracy of the model was $89 \%$ with $100 \%$ sensitivity and $76 \%$ specificity. CART analysis indicated that the interaction of longer jumps in the 5 -jump test $(>916 \mathrm{~cm})$ with more side difference in ankle dorsiflexion $\operatorname{ROM}\left(>2.5^{\circ}\right)$ and more knee valgus collapse in the non-reconstructed knee $(>-1.4 \mathrm{~cm})$ (relative risk, 4.03; 95\% confidence interval, 2.21-7.36) best predicted an increased likelihood of a second ACL injury.

Conclusions: The risk profiles selected by CART could accurately identify female soccer players at high risk for a second ACL injury. There was an interaction between functional performance, clinical assessment, and psychological factors, and it is reasonable to include these factors in return-to-sport decisions and in athletes screening after ACL injury.

\section{What is known about the subject}

Anterior cruciate ligament (ACL) injury is a severe and common injury in female soccer players. Return to sport is an important clinical outcome after ACL reconstruction (ACLR). However, the risk of sustaining a second ACL injury is increased with a return to cutting and pivoting sports after ACLR. Different risk factors such as young age, early return to sport, knee valgus motion, and impaired postural control have been associated with sustaining a second ACL injury. Previous studies evaluating risk factors to sustain a second ACL injury have used typical statistics tools, such as logistic or Cox proportional hazard regression analysis. Typical statistic tools cannot reveal complex interaction among various risk factors. Risk factors associated with sustaining a second ACL injury are probably of a more complex nature and need further investigation. 


\section{What this study adds to existing knowledge}

The risk profiles selected by classification and regression tree (CART) analysis can accurately identify female soccer players at high risk for a second ACL injury with a total accuracy of $89 \%$. The CART analysis showed that a second ACL injury was predicted only through interactions between functional performance, clinical assessment, and psychological factors. Therefore, it is reasonable to include these factors in return-to-sport decisions to improve safe return. Moreover, continuous follow-up assessments should be performed in female soccer players after ACLR.

\section{INTRODUCTION}

Anterior cruciate ligament (ACL) injuries are common in female soccer players, and women have a 2- to 3-fold higher injury risk than men. ${ }^{46}$ Injury prevention exercise programs in the high-risk group of female soccer players have focused on plyometric exercises, postural control, lower limb motor control, and lower limb and core strengthening. ${ }^{52}$ These programs target proposed intrinsic risk factors, such as biomechanical and neuromuscular deficits, by training in landing technique, knee control (i.e., avoiding knee valgus motion), postural control, lower limb and core strengthening. ${ }^{2}$ A summary of a meta-analysis showed a $67 \%$ ACL injury reduction rate for non-contact injuries in females after using such programs. ${ }^{52}$

Unfortunately, a high proportion of female soccer players sustain not only a first ACL injury but also a second ACL injury. The rate of secondary ACL injury is as high as $25 \%-$ $35 \%$ within 2-10 years after ACL reconstruction (ACLR) in younger athletes. ${ }^{3,17,39,49}$ Secondary prevention of ACL injury after ACLR is important because of the negative consequences of ACL injury both in the short and long term. Thus, risk factors associated with sustaining a second ACL injury must be investigated. ${ }^{47}$ 
Proposed risk factors for a second ACL injury include young age at first injury, $8,16,25,48,51$, ${ }^{54}$ return to cutting and pivoting sports, $, 3,17,39,51,54$ early return to sport after primary ACLR, $,{ }^{6}, 10,18$ impaired postural control, ${ }^{40}$ and reduced hip and knee control during landing measured with three-dimensional analysis. ${ }^{40}$ The association between athletes' functional performance, evaluated with different clinical test batteries, and the risk of sustaining a second ACL injury need further validation. ${ }^{30,53}$ Most of the previous studies investigating risk factors for a second ACL injury have typically used statistical tools such as logistic or Cox proportional hazard regression analysis, however the risk factors associated with ACL injury are more complex, and injuries do not arise from a linear combination of isolated predictive factors. ${ }^{7}$ Many different factors such as age, sex, functional performance, psychological factors, social/contextual factors, and surgical factors probably affect the outcome. ${ }^{5}$ To uncover this complex nature of risk factors, a complex systems approach is necessary. Classification and regression tree (CART) analysis allows the identification of non-linear interactions among predictors and makes clinical use of these interactions. To our knowledge, CART analysis has previously been used only in one study investigating risk factors for a second ACL injury. ${ }^{37}$

The aim of this study was to investigate the combinations of various clinical risk factors, by means of CART analysis, that are associated with secondary ACL injury in female soccer players after a primary unilateral ACLR.

\section{MATERIALS AND METHODS}

\section{Design}

This is a prospective cohort study on different interactions between factors associated with a second ACL injury in female soccer players with a previous ACLR. 


\section{Participants}

Those meeting inclusion criteria were active female soccer players, aged 16-25 years at the time of selection, who had undergone one primary ACLR between 6 and 36 months before the onset of the study and had returned to soccer at any level. A total of 117 female soccer players (mean age \pm standard deviation [SD], $20 \pm 2$ years, $19 \pm 9$ months after ACLR) were included. The players were recruited from the Swedish National Knee Ligament Register $(\mathrm{SNKLR})^{27}$ and via local soccer leagues to capture players with ACLR who were not registered in the SNKLR (Figure 1). All players were included in the study at the same time point in the soccer pre-season (January-April 2013, 2014, and 2015). Players who had already sustained a second ACL injury, had surgically treated injuries to either the medial or lateral collateral ligament, and/or with an associated posterior cruciate ligament injury were excluded. All players received written and oral information about the study. The study was approved by the Swedish Ethical Review Authority (Dnr 2012/24-31 and 2013/75-32) and the SNKLR board. For a detailed description of the inclusion procedure, see previously published data. $^{15,17}$

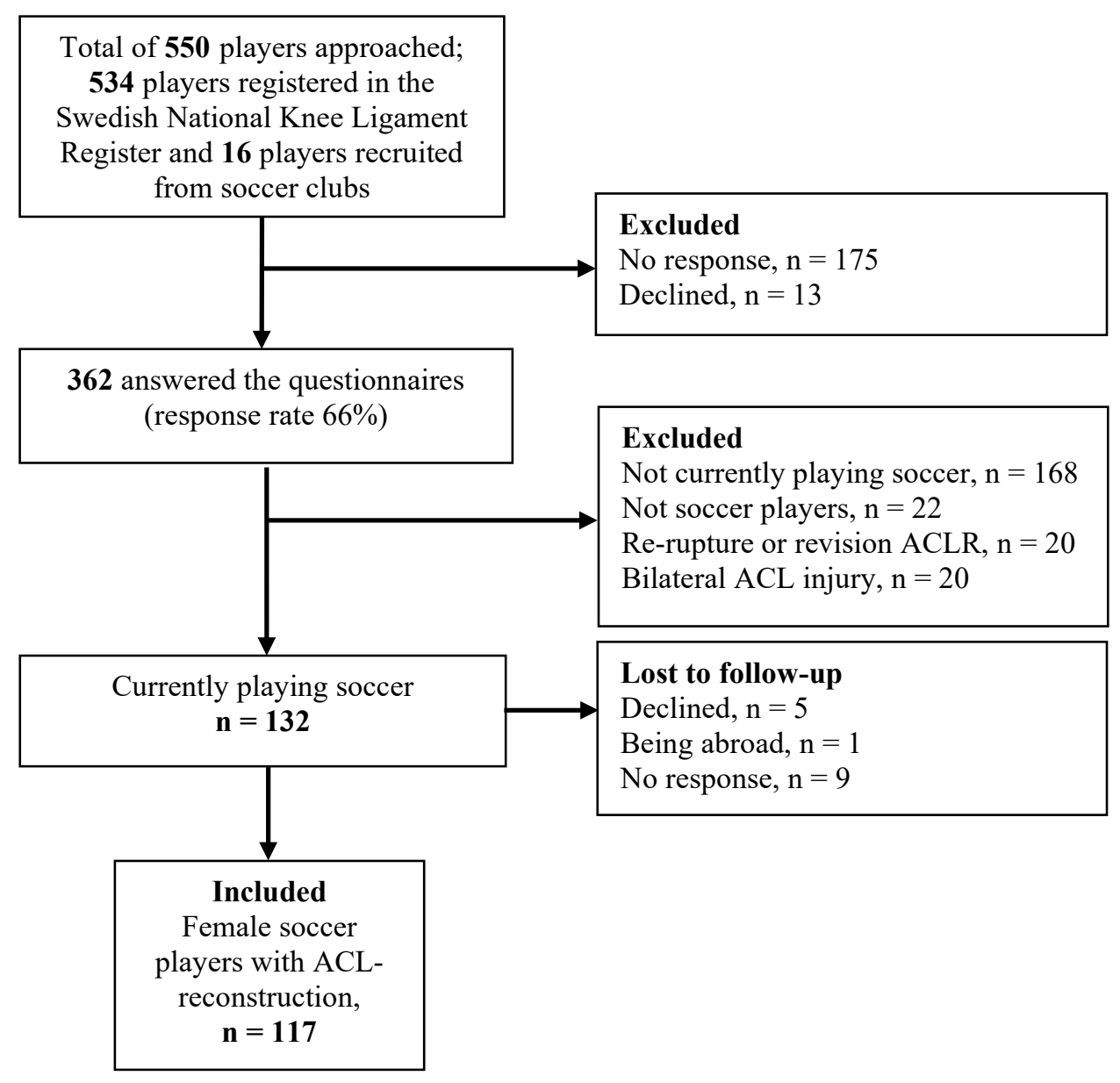


Figure 1. Study flowchart. ACL, anterior cruciate ligament; ACLR, anterior cruciate ligament reconstruction.

\section{Procedure}

At baseline, all players completed questionnaires, were assessed by clinical measurement, and performed functional performance tests. All questionnaires and tests are summarized in the Supplemental Appendix described in detail in previously published data. ${ }^{15,17}$ Surgical data were collected from SNKLR. Player-reported data were obtained through a battery of questionnaires evaluating knee function, knee-related quality of life and psychological readiness; the Knee injury and Osteoarthritis Outcome score (KOOS), ${ }^{43}$ International Knee Documentation Committee Subjective Knee Evaluation Form (IKDC), ${ }^{23,}{ }^{24}$ ACL-Quality of Life (ACL-QoL), ${ }^{31}$ and ACL-Return to Sport after Injury (ACL-RSI). ${ }^{28,}{ }^{50}$ Personality was assessed with the Swedish Universities Scales of Personality (SSP), ${ }^{20}$ which comprises 91 questions that highlight 13 stable personality traits (somatic anxiety, psychic anxiety, stress susceptibility, lack of assertiveness, impulsiveness, adventure seeking, detachment, social desirability, embitterment, trait irritability, mistrust, verbal trait aggression, and physical trait aggression). The score is summarized for each personality trait and computed into a normative standard $\mathrm{T}$ score. The $\mathrm{T}$ score is constructed to have a mean of 50 and an SD of 10 , and values $>50$ indicate higher levels of the personality traits. Perfectionism in sports (considered an enduring personality trait) ${ }^{21}$ was assessed with the Sport Multidimensional Perfectionism Scale (SMPS). ${ }^{11}$ It consists of 30 statements, divided into 4 dimensions of "perfectionism" in sport. Each statement has 5 possible answers from $1=$ strongly disagree to $5=$ absolutely agree. Sub-statements give an average value (1-5) with higher scores indicating a high degree of perfectionism. 
All measurements of anthropometrics and functional performance tests were conducted in a single test session, supervised by the same experienced test leader (A.F.), and according to a test protocol following a standard order: (1) height; (2) weight; (3) ankle range of motion $(\mathrm{ROM})$ in a weight-bearing position using a goniometer; ${ }^{26}(4) \mathrm{knee}$ ROM measured in the supine position using a goniometer; (4) the Star Excursion Balance Test (SEBT); ${ }^{42}$ (5) the single hop for distance; ${ }^{19}$ (6) the 5 -jump test $;^{9}$ (7) the drop vertical jump (DVJ); ${ }^{34-36}$ (8) the tuck jump; ${ }^{33}$ and (9) the side hop. ${ }^{19}$ A detailed description of the tests and test procedures have been published previously. ${ }^{15}$

A Limb Symmetry Index (LSI) was calculated ([ACL - reconstructed limb/uninvolved limb] $\times 100$ ) and used as a variable for the SEBT, single hop for distance, and side hop. The DVJ, tuck jump, and side hop were filmed using 2 video cameras (Panasonic HC-V500M) in the sagittal and frontal planes. Knee motion (medial/valgus or lateral/varus knee displacement) was measured with motion analysis software Dartfish ProSuite (Dartfish Ltd, Fribourg, Switzerland) from the captured video films. Knee motion was calculated in centimeters as the frontal plane displacement of the knee from the initial contact (when the feet just touched the ground) to the end of the deceleration phase (deepest knee flexion position) of the DVJ. ${ }^{34-36}$

\section{Factors Included in CART Analysis}

First, all authors independently rated which factors (from a total of 119 variables available from the baseline evaluation; Supplemental Appendix) they considered most important and clinically relevant to be included in the analysis based on literature review and clinical experience. The ratings were then discussed several times by the authors to achieve consensus, and 24 preliminary factors were included in the analysis. Before running the CART, a correlation matrix was performed within the questionnaires, and it was identified 
that KOOS and IKDC were strongly correlated $(\mathrm{r}=.74, P<.0001)$. To avoid too many questionnaires being included in the model and to prevent splits that could overlap each other, the IKDC was kept in the CART analysis and the KOOS sub-scales were removed. With regard to the SEBT, the range of distribution was identified to be around 100, meaning that this sample did not have limb asymmetry (mean, 100; range, 92-106). Therefore, the SEBT was taken out of the model, and we ended up with 19 of the 24 factors included in the CART analyses (Table 1 and Supplemental Appendix).

\section{Follow-Up of Second ACL Injury}

The players answered web-based questions on 3 occasions annually (pre-season, in-season, and post-season) and were followed up for 2 years from baseline inclusion. Players were asked to register any new knee injuries from playing soccer using a physical complaint definition: "any physical complaint sustained by a player irrespective of the need for medical attention or time-loss from soccer activities." 13 If a player reported a new knee injury she was contacted by telephone for further information and to confirm if it was a new ACL injury whether it was a re-rupture or contralateral rupture. Confirmation of the diagnosis was retrieved from medical records. Detailed descriptions of registered new knee injuries and other injuries have been published previously for the cohort. ${ }^{17}$

\section{Statistical Methods}

All statistical analyses were performed with IBM SPSS Statistics for Windows (v 24.0; IBM) and OpenEpi software. Mean \pm SD or median and interquartile range (IQR)/range were calculated to characterize the sample. Between-group comparisons were made with the Student $t$ test, Mann-Whitney $U$ test or the chi-square test as appropriate. The significance level was set at $P<.05$. CART analysis was used to determine which interactions between factors were associated with secondary ACL injury. Throughout binary recursive divisions of 
the initial set of data, CART selects the predictors and their respective cut-off points to achieve the best classification regarding individuals in each category (with and without secondary ACL injury). The predictors are selected hierarchically based on the strength of association with the outcome variable (secondary ACL injury). For each partition, CART analysis considers all variables to decide which one would be the best to split the parent node in two. The CART model begins with the total sample ( $\mathrm{n}=117$; node 0$)$, and it is divided in to 2 groups according to the specific variable and cut-off value. This process is applied again (recursively) until the sub-groups reach a minimum size or no improvement can be done. Therefore, all splits and predictors selection were done by CART, based on the analysis criteria, and it is free from authors' bias.

The following criteria were used to produce the partitions and, consequently, model growth: a minimum of 8 participants in each node to make a division, a minimum of 4 participants to generate a node, ${ }^{32}$ and a Gini index of .0001 to maximize the node's homogeneity. A pruning procedure aps applied to avoidoverfitting partitions. We used 5-fold cross-validation to estimate a better accuracy and improve the level of fit of the model. The cross-validation is a resampling procedure used to evaluate machine-learning models on a limited data sample. ${ }^{32}$ Cross-validation is a powerful preventative measure against overfitting. The classification cost was considered symmetric between categories, and secondary ACL injury probability was established as equal between groups. A receiver operating characteristic (ROC) curve was created to verify the accuracy of the model and, finally, relative risks (RR) were calculated for each terminal node of the CART model to investigate the strength of associations. The cross-validation procedure is about estimating the accuracy, not improving the accuracy. Meaning that with cross-validation you can improve the accuracy of the measurement (robust analyses), but not improve the accuracy of the model. 


\section{RESULTS}

Twenty-nine players (25\%) sustained a second ACL injury (22 ipsilateral and 7 contralateral ruptures). All ACL injuries occurred while playing soccer except one re-rupture of the ACL graft, which occurred during skiing and was therefore not included in the analyses. Thus, in the final CART analysis, 28 players were included in the secondary ACL injury group and 89 players in the group without secondary ACL injury. The reported data of new ACL injuries during the 2-year follow-up were complete. Descriptive statistics for demographic characteristics and the 19 predictors for the study sample are presented in Table 1. 


\section{TABLE 1}

Descriptive Demographic and 24 Independent Factors with 19 Included in the Classification and Regression Tree (CART) Analysis of the Entire Sample, Separated into Those With and Without Secondary ACL Injury ${ }^{a}$

\begin{tabular}{|c|c|c|c|c|c|}
\hline Variables & $\begin{array}{c}\text { Total } \\
\text { Sample } \\
(\mathrm{n}=117), \\
\text { Range }\end{array}$ & $\begin{array}{c}\text { Total Sample } \\
(\mathrm{n}=117), \\
\text { Mean } \pm \mathrm{SD} \\
\text { or Median } \\
(\mathrm{IQR}, \text { Range) }\end{array}$ & $\begin{array}{c}\text { Players with } \\
\text { Secondary ACL } \\
\text { Injury }(\mathrm{n}=28)\end{array}$ & $\begin{array}{c}\text { Players } \\
\text { without } \\
\text { Secondary } \\
\text { ACL Injury } \\
(\mathrm{n}=89) \\
\end{array}$ & $P$ \\
\hline Age, years & $16-26$ & $20 \pm 2$ & $20 \pm 3$ & $20 \pm 2$ & .613 \\
\hline Height, cm & $153-180$ & $168 \pm 5$ & $167 \pm 5$ & $168 \pm 5$ & .641 \\
\hline Body mass index, $\mathrm{kg} / \mathrm{m}^{2}$ & $18.2-30.9$ & $23.0 \pm 2.6$ & $22.7 \pm 2.5$ & $23.1 \pm 2.7$ & .465 \\
\hline Graft: all autografts & & & & & .135 \\
\hline Hamstrings & & & $26(93)$ & $88(99)$ & \\
\hline Patellar tendon & & & $1(4)$ & $1(1)$ & \\
\hline Quadriceps & & & $1(4)$ & & \\
\hline Graft diameter, mm & $6.0-10.0$ & $8.0 \pm 0.6$ & $8.1 \pm 0.7$ & $8.0 \pm 0.6$ & .458 \\
\hline$<8.0$ & & & $9(32)$ & $33(37)$ & .635 \\
\hline$\geq 8.0$ & & & $19(68)$ & $56(63)$ & \\
\hline Fixation in tibia & & & & & .122 \\
\hline Cortical & & & $15(54)$ & $33(37)$ & \\
\hline Intratunnel fixation & & & $13(46)$ & $56(63)$ & \\
\hline Fixation in femur & & & & & .336 \\
\hline Cortical & & & $28(100)$ & $84(94)$ & \\
\hline Intratunnel fixation & & & $0(0)$ & $5(6)$ & \\
\hline \multicolumn{6}{|l|}{ Presence of concomitant injuries at ACLR } \\
\hline Meniscus injury (medial/lateral) & & & $15(54)$ & $34(38)$ & .151 \\
\hline Articular cartilage injury & & & $3(11)$ & $8(9)$ & .723 \\
\hline Meniscus- and/or cartilage injury & & & $15(54)$ & $36(40)$ & .222 \\
\hline 1. Time between injury and ACLR, months & $0-23$ & $3(5,0-22)$ & $3(4,1-11)$ & $5(5,0-23)$ & .051 \\
\hline 2. Level of play, n (\%) & & & & & .395 \\
\hline Elite (2 top divisions) & & $14(12)$ & $4(14)$ & $10(11)$ & \\
\hline 3rd-6th division & & $91(78)$ & $23(82)$ & $68(76)$ & \\
\hline Lowest division or youth play & & $12(10)$ & $1(4)$ & $11(12)$ & \\
\hline 3. IKDC (0-100) & $53-100$ & $84 \pm 11$ & $85 \pm 11$ & $84 \pm 12$ & .588 \\
\hline 4. ACL-RSI (0-10) & $2.3-10$ & $6.8 \pm 1.8$ & $6.9 \pm 1.9$ & $6.8 \pm 1.8$ & .898 \\
\hline 5. ACL-QoL (0-10) & $3.6-9.7$ & $7.6 \pm 1.4$ & $7.7 \pm 1.5$ & $7.6 \pm 1.4$ & .595 \\
\hline 6. KOOS - Symptom $(0-100)$ & $21-100$ & $84 \pm 13$ & $86 \pm 10$ & $83 \pm 14$ & .192 \\
\hline 7. KOOS - Pain $(0-100)$ & $58-100$ & $91 \pm 9$ & $92 \pm 7$ & $90 \pm 10$ & .563 \\
\hline 8. KOOS - Sport/Recreation $(0-100)$ & $10-100$ & $79 \pm 19$ & $82 \pm 16$ & $77 \pm 20$ & .246 \\
\hline 9. KOOS - QoL $(0-100)$ & $25-100$ & $72 \pm 17$ & $70 \pm 16$ & $72 \pm 17$ & .459 \\
\hline 10. SMPS - Personal Standards (1-5) & $1-5$ & $3.2 \pm 0.9$ & $3.4 \pm 0.8$ & $3.2 \pm 1.0$ & .233 \\
\hline 11. SSP - Somatic anxiety (0-100) & $34-76$ & $52 \pm 8$ & $52 \pm 8$ & $52 \pm 9$ & .774 \\
\hline 12. SSP - Psychic anxiety $(0-100)$ & $32-77$ & $51 \pm 10$ & $53 \pm 9$ & $51 \pm 10$ & .363 \\
\hline 13. SSP - Stress susceptibility $(0-100)$ & $29-85$ & $52 \pm 10$ & $53 \pm 9$ & $51 \pm 10$ & .338 \\
\hline 14. SSP - Impulsiveness (0-100) & $28-75$ & $51 \pm 9$ & $51 \pm 6$ & $51 \pm 10$ & .662 \\
\hline 15. SSP - Adventure seeking (0-100) & $36-75$ & $54 \pm 8$ & $53 \pm 6$ & $55 \pm 9$ & .328 \\
\hline 16. Ankle dorsiflexion, side difference ROM, ${ }^{\circ}$ & -8 to 5 & $0 \pm 2.0$ & $0 \pm 1.5$ & $1 \pm 2.1$ & .059 \\
\hline 17. Knee extension ACLR leg, ${ }^{\circ}$ & -15 to 20 & $-5 \pm 6$ & $-7 \pm 4$ & $-5 \pm 6$ & .044 \\
\hline 18. LSI - single hop for distance, $\%$ & $76-122$ & $98 \pm 8$ & $99 \pm 9$ & $98 \pm 8$ & .630 \\
\hline 19. LSI - side hop, \% & $0-139$ & $93 \pm 21$ & $97 \pm 19$ & $92 \pm 22$ & .237 \\
\hline 20. 5-jump test, $\mathrm{cm}$ & $633-1201$ & $878 \pm 98$ & $922 \pm 116$ & $865 \pm 88$ & .007 \\
\hline 21. Tuck jumps total points $(0-10)$ & $1-9$ & $5 \pm 2$ & $5 \pm 2$ & $5 \pm 2$ & .286 \\
\hline 22. Knee collapse ACLR leg in DVJ, cm & -7.9 to 10.7 & $\begin{array}{c}2.7(2 \\
-7.9 \text { to } 10.7)\end{array}$ & $\begin{array}{c}2.8(6, \\
-2.6 \text { to } 10.7)\end{array}$ & $\begin{array}{c}2.7(4 \\
-7.9 \text { to } 9.3)\end{array}$ & .853 \\
\hline 23. Knee collapse non-ACLR leg in DVJ, cm & -10 to 10.9 & $\begin{array}{c}3.7(2, \\
-10.0 \text { to } 10.9)\end{array}$ & $\begin{array}{c}4.5(4 \\
-0.9 \text { to } 9)\end{array}$ & $\begin{array}{c}3.5(6, \\
-10.0 \text { to } 10.9)\end{array}$ & .326 \\
\hline 24. Normalized SEBT composite score, LSI, $\%^{b}$ & $92-106$ & $100 \pm 3$ & $100 \pm 2$ & $100 \pm 3$ & .642 \\
\hline
\end{tabular}


${ }^{a}$ Variables in bold are included in the CART analysis. ACL, anterior cruciate ligament; ACL-QoL, ACL-quality of life;

ACLR, anterior cruciate ligament reconstruction; ACL-RSI, anterior cruciate ligament - return to sport after injury; DVJ, drop vertical jump; IKDC, International Knee Documentation Committee Subjective Knee Form; KOOS, The Knee injury and Osteoarthritis Outcome Score; LSI, Limb Symmetry Index; ROM, range of motion; SD, standard deviation; SEBT, Star Excursion Balance Test; SMPS, Sport Multidimensional Perfectionism Scale; SSP, the Swedish Universities Scales of Personality.

\section{CART Model and Relative Risk}

The classification tree identified 9 of the 19 independent variables associated with secondary ACL injury (Figure 2). The 5-jump test was the first predictor selected by the CART model, with a cut-off of $916 \mathrm{~cm}$. In players with shorter jumps in the 5-jump test, $\mathrm{SSP}$ stress susceptibility was the second predictor (cut-off point of 44), followed by SSP-adventure seeking (cut-off point of 53), ACL-RSI (cut-off point of 5.8), LSI on side hop (cut-off point of 97\%), tuck jump (cut-off point of 7.5) and LSI on single hop for distance (cut-off point of 102\%). For players who had a 5 -jump test longer than the cut-off point, the model selected side difference in ankle dorsiflexion ROM as the second predictor (cut-off point of $-2.5^{\circ}$ ), followed by knee collapse on the non-ACLR leg in DVJ (cut-off point of $-1.4 \mathrm{~cm}$ ) as the third predictor.

The model indicated that the interactions among predictors of nodes 10,15 , and 18 were statistically associated with secondary ACL injury in female soccer players. The interaction of longer jumps in the 5-jump test with more side difference in ankle dorsiflexion ROM and more knee collapse in the DVJ was best at predicting an increased likelihood of sustaining a second ACL injury (terminal node 10). There was an interaction between physical (5-jump test and tuck jump) and psychological factors (SPP-stress susceptibility, SPP-adventure seeking, and ACL-RSI) in the second risk profile (terminal node 15). The third risk profile 
(terminal node 18) also showed an interaction between physical (5-jump test, LSI in side hop and in single hop for distance) and psychological factors (SPP-stress susceptibility and SPPadventure seeking). The interactions representing the risk profiles to sustain a secondary ACL injury and the relative risk for each terminal node and the strength of the associations of predictors with the outcome are illustrated in Table 2.

The CART model correctly predicted 28 of the 28 players with secondary ACL injury (100\% sensitivity) and 68 of the 89 players without secondary ACL injury (76\% specificity). Therefore, the risk profiles identified encompass all injured players of the sample, meaning that the high sensitivity of the model rules out second ACL injury if the athlete is in a protective profile (nodes $3,5,9,11,13,16$ and 17). The total correct classification was $82 \%$, and the area under the ROC curve (accuracy) was 0.89 (95\% confidence interval, $0.82-0.94$; standard error, $0.03 ; P<.0001)$, indicating that the model's classification was not due to chance.

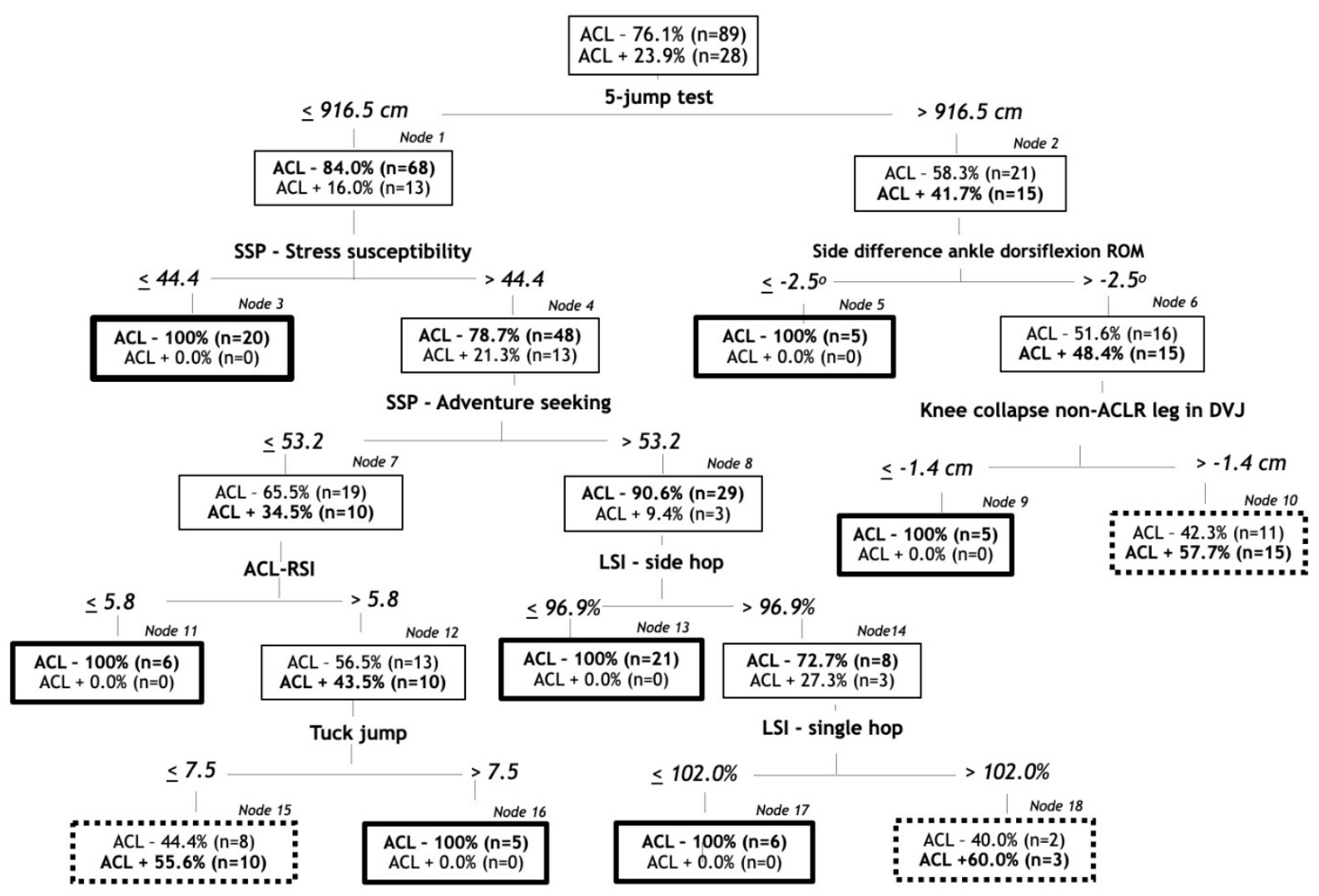


Figure 2. Classification and regression tree model for secondary ACL injury. The bold text in each node (ACL-,[no secondary ACL injury], or ACL+,[secondary ACL injury]) corresponds to the predicted category. The classification profile for increased likelihood of sustaining a secondary ACL injury (ㅁash boxes) at the terminal node was as follows:

Node 10; 5JT $>916 \mathrm{~cm}$, side difference ankle dorsiflexion ROM $>-2.5^{\circ}$, and knee collapse in the non-ACLR leg in DVJ $>-1.4 \mathrm{~cm}$.

Node 15: $5 \mathrm{JT}<916 \mathrm{~cm}$, SPP-stress susceptibility $>44$, SPP-adventure seeking $\leq 53$, ACL-RSI $>5.8$ and tuck jump $\leq 7.5$.

Node 18: $5 \mathrm{JT}<916 \mathrm{~cm}$, SPP-stress susceptibility $>44$, SPP-adventure seeking $>53$, LSI-side hop $>97 \%$, and LSI- single hop for distance $>102 \%$.

The classification profile for decreased likelihood of sustaining a secondary ACL injury (bold $\underline{\text { boxes) }}$ at the terminal node was as follows:

Node 3: $5 \mathrm{JT} \leq 916 \mathrm{~cm}$ and SPP-stress susceptibility $\leq 44$.

Node 5: 5JT $>916 \mathrm{~cm}$, side difference ankle dorsiflexion $\mathrm{ROM} \leq-2.5^{\circ}$.

Node 9: 5JT $>916 \mathrm{~cm}$, side difference ankle dorsiflexion $\mathrm{ROM}>-2.5^{\circ}$, and knee collapse non-ACLR leg in DVJ $\leq-1.4 \mathrm{~cm}$.

Node 11: $5 \mathrm{JT} \leq 916 \mathrm{~cm}$, SPP-stress susceptibility $>44$, SPP-adventure seeking $\leq 53$, and ACL$\mathrm{RSI} \leq 5.8$.

Node 13: $5 \mathrm{JT} \leq 916 \mathrm{~cm}$, SPP-stress susceptibility $>44$, SPP- adventure seeking $>53$, and LSIside hop $\leq 97 \%$.

Node 16: $5 \mathrm{JT} \leq 916 \mathrm{~cm}$, SPP-stress susceptibility $>44$, SPP-adventure seeking $\leq 53$, ACL-RSI $>5.8$, and tuck jump $>7.5$. 
Node 17: $5 \mathrm{JT} \leq 916 \mathrm{~cm}$, SPP-stress susceptibility $>44$, SPP-adventure seeking $>53$, LSI-side hop $>97 \%$, and LSI-single hop for distance $\leq 102 \%$.

ACL-, no second ACL injury; ACL+, second ACL injury; ACLR, anterior cruciate ligament reconstructed; ACL-RSI, anterior cruciate ligament-return to sport after injury; 5JT, 5jump test; LSI, Limb Symmetry Index.

\section{TABLE 2}

Risk Profiles (Interactions) With Increased Likelihood of Sustaining a Secondary ACL injury From the Classification and Regression Tree (CART) model ${ }^{a}$

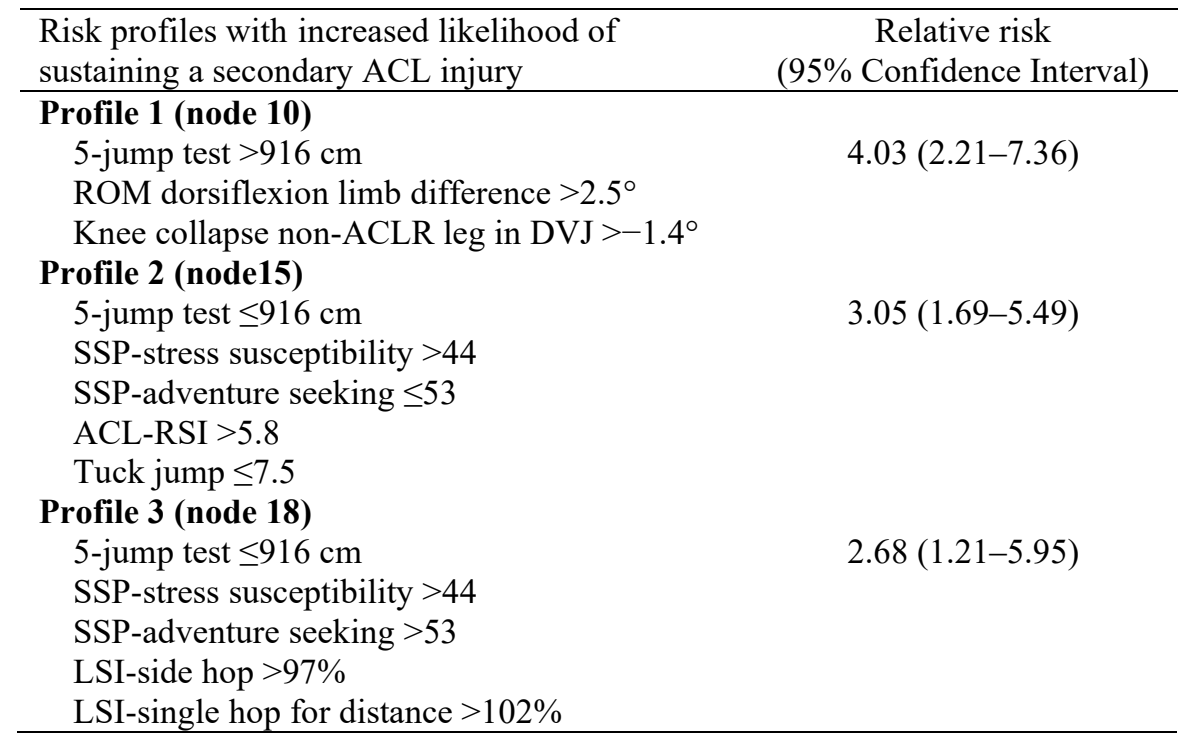

ACL-RSI, anterior cruciate ligament injury-return to sport after injury; DVJ, drop vertical jump; LSI, limb symmetry index; ROM, range of motion. SSP, the Swedish Universities Scales of Personality. 


\section{TABLE 3}

Profiles (Interactions) for Decreased Likelihood of Sustaining a Secondary ACL Injury from the Classification and Regression Tree (CART) model $^{a}$

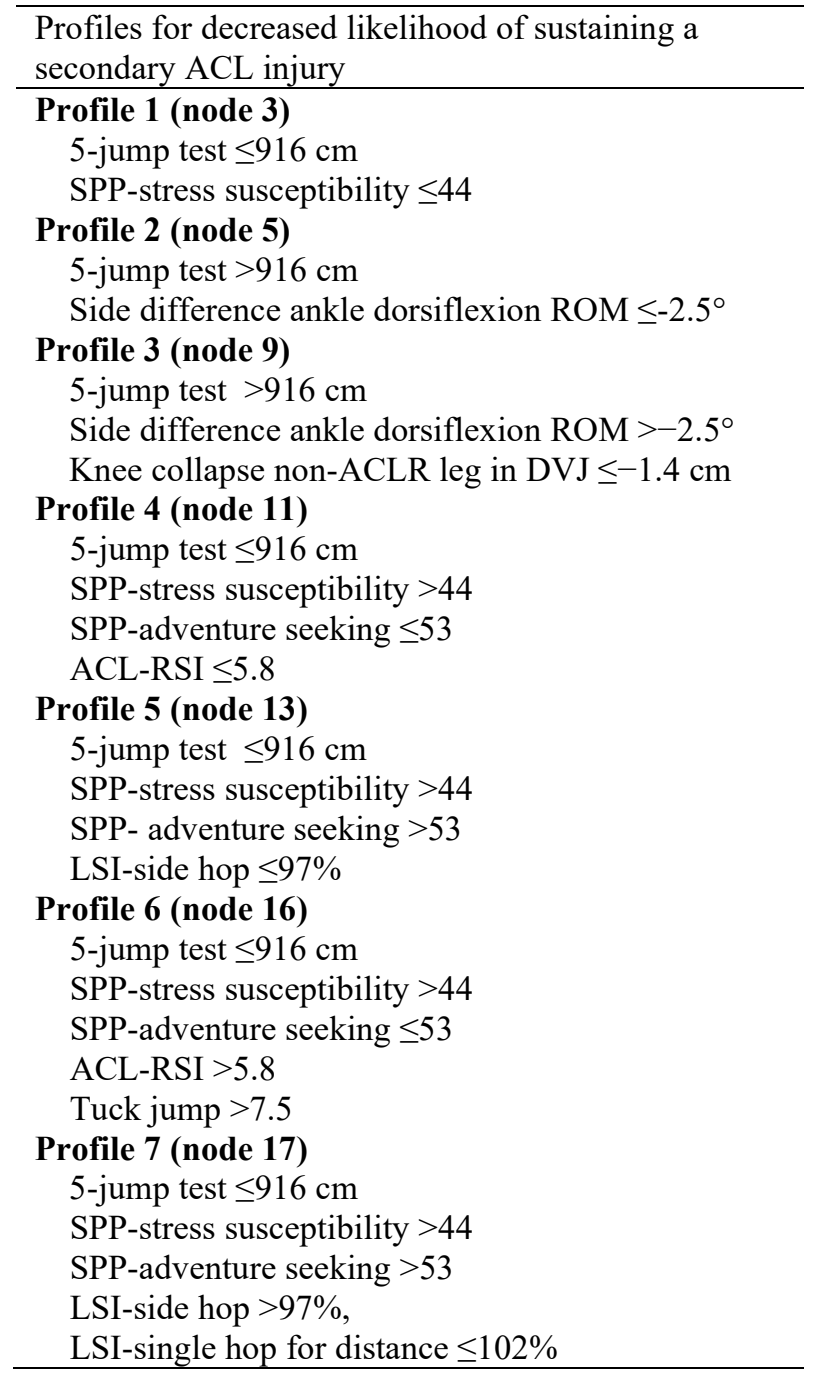

${ }^{a}$ In terminal nodes $3,5,9,11,13,16$, and 17 , it was not possible to calculate the relative risk because all athletes $(100 \%)$ were classified as not having a secondary ACL injury.

\section{DISCUSSION}

The main finding was that CART analysis identified 3 different risk profiles for a second ACL injury in female soccer players with a previous ACLR. The interaction between physical and psychological factors, with player-reported data and standard clinical measures, identified players at high risk for second ACL injury after ACLR. Interestingly, the CART model 
revealed that a second ACL injury could not be predicted by an isolated factor, but only through interactions among them.

It is complex to evaluate and determine whether a soccer player with ACLR has good knee function and a low risk of sustaining a second ACL injury. The CART analysis selected 9 factors associated with second ACL injury using (a) functional tests: jump length in the 5jump test, knee collapse on the non-ACL reconstructed leg in the DVJ, number of flaws in the tuck jump, LSI on side hop, and the single hop for distance; (b) clinical assessment: side difference in ankle dorsiflexion ROM; and (c) player-reported data score for: ACL-RSI, SSPsusceptibility, and SSP-adventure seeking. The first risk profile showed an interaction between functional performance measured with distance hopped, qualitative assessment of knee collapse, and side-to-side asymmetry in ankle dorsiflexion ROM. Players who had good performance (jumped longer) on the 5-jump test $(>916 \mathrm{~cm})$, but more than $2.5^{\circ}$ of dorsiflexion ROM deficiency and presence of more knee collapse on the non-ACLR leg, had a 4-fold risk of sustaining a second ACL injury. No previous study evaluating isolated risk factors associated with a second ACL injury has, to our knowledge, shown any association between the 5-jump test and second ACL injury. Ankle dorsiflexion restriction could overload the knee joint, because a person with less dorsiflexion ROM exhibits a more erect posture during the drop landing task. ${ }^{22}$ For an increase of $1^{\circ}$ in ankle dorsiflexion ROM, there is a $38 \%$ decrease in the probability of sustaining a primary ACL injury in male athletes. ${ }^{4}$ Female athletes with ACLR who sustain a second ACL injury demonstrated a more rigid pattern of movement at the ankle, ${ }^{38}$ which could be due to decreased dorsiflexion ROM. Also knee collapse measured with DVJ could increase knee demand and the likelihood of sustaining a second ACL injury. ${ }^{40}$ Therefore, bilateral performance tests such as the 5-jump test and DVJ should be assessed together with clinical assessment after an ACLR. 
The other 2 risk profiles showed an interaction between physical and psychological factors. In the second risk profile, players who had low performance (jumped shorter) on the 5-jump test $(\leq 916 \mathrm{~cm})$, had high stress susceptibility $>44$, low adventure seeking $\leq 53$, estimate high psychological readiness (emotions, risk appraisal, and confidence in knee function and performance) for return to sport in ACL-RSI $>5.8$, and performed well in the tuck jump $\leq 7.5$, were 3 times more likely to sustain a second ACL injury. In the third risk profile, players with low performance on the 5-jump test $(\leq 916 \mathrm{~cm})$, stress susceptibility $>44$, high adventure seeking $>53$, and performed well in the side hop with LSI $>97 \%$, and the single hop for distance with LSI $>102 \%$, had an almost 3 times higher risk of sustaining a second ACL injury. In agreement with our results and using a CART analysis, Paterno et al ${ }^{37}$ identified 2 risk profiles for a secondary ACL injury. Both risk profiles included physical and psychological factors, i.e., functional performance on the triple hop for distance test in both distances hopped and LSI, and high self-reported knee confidence. However, the only psychological factor analyzed was self-reported knee confidence from a single question in the KOOS quality of life sub-scale. In their model, the single most common factor in both profiles was young age ( $<19$ years old), a factor that we did not include in our analysis because of the narrow age range in our cohort. In addition, female sex was identified to interact with the other factors. These analyses show complex risk profiles for a second ACL injury that cannot be identified with a linear approach of isolated variables as reported in most of the existing literature evaluating risk factors. $6,8,10,18,25,40,42,48,51$ Based on our results, it is reasonable to include functional performance tests, with qualitative assessment, and psychological factors in return-to-sport decisions but also in follow-ups after returning. Our data indicate that it is likely to be important to continue to evaluate the physical and psychological parameters of female soccer players with ACLR as long as they play soccer. 
The hierarchy of the predictors showed that the 5-jump test with a cut-off value of $916 \mathrm{~cm}$ was the main factor associated with a second ACL injury. The most commonly used hop tests to evaluate athletes after ACLR are single hop for distance, timed hop, triple hop for distance, and cross-over hop for distance. ${ }^{53}$ These hop tests are performed on a single leg and comparisons between the ACLR leg and non-ACLR leg are done to present an LSI value. The 5-jump test is proposed as a clinical alternative to evaluate lower limb explosive power in soccer players. ${ }^{9}$ The 5 -jump test does not require any sophisticated equipment, is easy to perform, and is more similar to a running movement than single hop tests. However, it is not possible to assess asymmetries with the 5-jump test, and our results showed the combinations of different tests and how they are complementary. Our results also showed that a longer jump could possibly increase stress in the knee joint and maybe put the athlete at risk. Non-linearity and interaction between factors show us that one variable, analyzed in isolation, could not always help us to understand injury risk. Clinicians should therefore not base their decision about injury risk solely on single factors. In the future, the 5-jump test may be a suitable test to include in the test battery when evaluating soccer players with ACLR.

Psychological factors had a great impact on our risk profiles. Stress susceptibility and adventure seeking were the second and third strongest predictors in the hierarchy of the predictors associated with secondary ACL injury. Negative life stress may influence the risk of sustaining an injury in soccer players. ${ }^{44}$ The SSP personality trait adventure seeking (avoiding routine and needing change and action) could be associated with risk behavior and playing style. In addition, high ACL-RSI, which was also included in the risk profile, could indicate high-risk appraisal. Our results may strengthen the assumption that elite female soccer players, who are at high risk of sustaining an ACL injury, may have a profile of risk factors that includes aggressive playing style and anatomic and neuromuscular characteristics. ${ }^{12}$ Previous studies have stressed the importance of including psychological 
factors in addition to functional factors in the evaluation of return to sport after ACLR. ${ }^{14,41}$ For instance, a higher score on the personality trait adventure seeking is reported to be associated with return to soccer after ACLR in females. ${ }^{14}$ The result in this study showed that it is also important to include psychological factors such as stress susceptibility in the evaluation of the player with an ACL injury for the association of sustaining a second ACL injury. Stressors, such as daily hassle, negative-life-event stress, or a high level of life stress should also be monitored over time. ${ }^{44}$

Our analyses showed that patient-reported outcomes of knee function and knee-related quality of life were not included as factors in any risk profile for a secondary ACL injury, which is in agreement with Paterno et al. ${ }^{37}$ However, patient-reported outcomes are important to evaluate clinical progress during rehabilitation, as well as in return-to-sport criteria, because of its association with return-to sport outcome. ${ }^{29}$

Other factors that were not included in a risk profile for a secondary ACL injury in the CART analysis were level of play and time between injury and ACLR. This is in contrast to the results of a previous study using Cox proportional hazard regression analysis, which reported that having ACLR early after the primary injury was predictive of revision and contralateral ACLR. ${ }^{16}$ To our knowledge, no study has reported this as a higher risk for a second ACL injury depending on playing level.

There were 7 low-risk profiles associated with no second ACL injury. Five of the profiles had shorter jumps on the 5-jump test with interaction of low or high stress susceptibility, and low or high adventure seeking. The 2 profiles with longer jumps in the 5-jump test had interactions with side difference ankle dorsiflexion ROM and less knee collapse on the nonACLR leg. There was an interaction between physical and psychological factors, similar to the identified risk profiles. It is just as important to discuss low-risk players as it is to find high-risk players. In the future, additional efforts could be on evaluating health factors. 
Our results should be interpreted with awareness that the study included an extremely highrisk group for a second ACL injury, young female soccer players with ACLR. 3, 8, 16, 17, 25, 39, 48, 51,54 Thus, the risk profile may differ in other populations. There are conflicting results on whether women in general are more prone to sustain a secondary ACL than men. ${ }^{45}$ However, Ahldén et $\mathrm{al}^{1}$ reported that over a 5 -year period after primary ACLR, the total additional ACLR rate for women who played soccer aged 15-18 years was $22 \%$ compared with only $9.8 \%$ for men of the same age. The generalizability of our findings to male soccer players, to athletes in other sports, or to inactive or older persons is unclear. The CART model is sample dependent, as any other statistics, and external validity is thus an important issue to consider.

In addition, the cut-offs in the identified risk profiles are created by the CART and should be interpreted with caution in the clinic. However, in clinical practice, it is important to evaluate the interactions of factors. Our results could help clinicians to decide which factors are important to assess in their players if the aim is to identify the risk for a second ACL injury.

The strengths of the present study include the homogeneous cohort of female soccer players with ACLR, the prospective design with verification of all new ACL injuries from medical charts, and no missing data. Another strength is the breadth of factors included in the CART analysis, with extensive questionnaires evaluating injury characteristics, psychological aspects, player-reported function and quality of life, anthropometrics measurements, and functional performance tests evaluating postural control, endurance, maximum hop length, and movement asymmetries. All factors were agreed on by the experienced authors, based on current evidence and clinical meaningfulness, before inclusion in the CART model. The model had good accuracy with a total accuracy of $89 \%$.

Some limitations should be acknowledged. This was a relatively small sample with a small number of second ACL injuries. Therefore, both ipsilateral and contralateral ACL injuries 
were analyzed together, and we could not study specific interactions of predictor variables for each outcome. A higher sample size could have identified other subgroups and augmented the external validity of those found in this study. The lack of an a priori sample size calculation is a limitation, although the high accuracy of the CART model suggests our included sample was sufficient for the main analyses.

\section{CONCLUSIONS}

The risk profiles identified by CART showed that interactions between functional performance tests, clinical assessment, and psychological factors could accurately classify female soccer players at high risk of sustaining a second ACL injury. Based on our findings, the recommendation is to include functional performance tests, with qualitative assessment, clinical assessment, and psychological factors in return-to-sport decisions, but also include continuous follow-up assessments as long as the females with ACLR play soccer.

\section{REFERENCES}

1. Ahldén M, Samuelsson K, Sernert N, Forssblad M, Karlsson J, Kartus J. The Swedish National Anterior Cruciate Ligament Register: a report on baseline variables and outcomes of surgery for almost 18,000 patients. Am J Sports Med. 2012;40(10):22302235. PMID: 22962296.

2. Alentorn-Geli E, Myer GD, Silvers HJ, et al. Prevention of non-contact anterior cruciate ligament injuries in soccer players. Part 2: a review of prevention programs aimed to modify risk factors and to reduce injury rates. Knee Surg Sports Traumatol Arthrosc. 2009;17(8):859-879. PMID: 19506834.

3. Allen MM, Pareek A, Krych AJ, et al. Are female soccer players at an increased risk of second anterior cruciate ligament injury compared with their athletic peers? Am J Sports Med. 2016;44(10):2492-2498. PMID: 27261476

4. Amraee D, Alizadeh MH, Minoonejhad H, Razi M, Amraee GH. Predictor factors for lower extremity malalignment and non-contact anterior cruciate ligament injuries in male athletes. Knee Surg Sports Traumatol Arthrosc. 2017;25(5):1625-1631. PMID: 26704803. 
5. Bahr R, Krosshaug T. Understanding injury mechanisms: a key component of preventing injuries in sport. Br J Sports Med. 2005;39(6):324-329. PMID: 15911600.

6. Beischer S, Gustavsson L, Senorski EH, et al. Young Athletes Who Return to Sport Before 9 Months After Anterior Cruciate Ligament Reconstruction Have a Rate of New Injury 7 Times That of Those Who Delay Return. J Orthop Sports Phys Ther. 2020;50(2):83-90. PMID: 32005095.

7. Bittencourt NFN, Meeuwisse WH, Mendonca LD, Nettel-Aguirre A, Ocarino JM, Fonseca ST. Complex systems approach for sports injuries: moving from risk factor identification to injury pattern recognition-narrative review and new concept. $\mathrm{Br} J$ Sports Med. 2016;50(21):1309-1314. PMID: 27445362.

8. Borchers JR, Pedroza A, Kaeding C. Activity level and graft type as risk factors for anterior cruciate ligament graft failure: a case-control study. Am J Sports Med. 2009;37(12):2362-2367. PMID: 19684294

9. Chamari K, Chaouachi A, Hambli M, Kaouech F, Wisloff U, Castagna C. The fivejump test for distance as a field test to assess lower limb explosive power in soccer players. J Strength Cond Res. 2008;22(3):944-950. PMID:18438217.

10. Dekker TJ, Godin JA, Dale KM, Garrett WE, Taylor DC, Riboh JC. Return to Sport After Pediatric Anterior Cruciate Ligament Reconstruction and Its Effect on Subsequent Anterior Cruciate Ligament Injury. J Bone Joint Surg Am. 2017;99(11):897-904. PMID: 28590374

11. Dunn JGH, Dunn JC, Syrotuik DG. Relationship between multidimensional perfectionism and goal orientations in sport. J Sport Exercise Psy. 2002;24(4):376395.

12. Faude O, Junge A, Kindermann W, Dvorak J. Risk factors for injuries in elite female soccer players. Br J Sports Med. 2006;40(9):785-790. PMID: 16825269.

13. Fuller CW, Ekstrand J, Junge A, et al. Consensus statement on injury definitions and data collection procedures in studies of football (soccer) injuries. Clin J Sport Med. 2006;16(2):97-106. PMID: 16603877

14. Fältström A, Hägglund M, Kvist J. Factors associated with playing football after anterior cruciate ligament reconstruction in female football players. Scand J Med Sci Sports. 2016;26(11):1343-1352. PMID: 26589671

15. Fältström A, Hägglund M, Kvist J. Functional performance among active female soccer players after unilateral primary anterior cruciate ligament reconstruction compared with knee-healthy controls. Am J Sports Med. 2017;45(2):377-385. PMID: 28146394.

16. Fältström A, Hägglund M, Magnusson H, Forssblad M, Kvist J. Predictors for additional anterior cruciate ligament reconstruction: data from the Swedish national ACL register. Knee Surg Sports Traumatol Arthrosc. 2016;24(3):885-894. PMID: 25366191. 
17. Fältström A, Kvist J, Gauffin H, Hägglund M. Female soccer players with anterior cruciate ligament reconstruction have a higher risk of new knee injuries and quit soccer to a higher degree than knee-healthy controls. Am J Sports Med. 2019;47(1):3140. PMID: 30481050.

18. Grindem H, Snyder-Mackler L, Moksnes H, Engebretsen L, Risberg MA. Simple decision rules can reduce reinjury risk by $84 \%$ after ACL reconstruction: the Delaware-Oslo ACL cohort study. Br J Sports Med. 2016;50(13):804-808. PMID: 27162233

19. Gustavsson A, Neeter C, Thomée P, et al. A test battery for evaluating hop performance in patients with an ACL injury and patients who have undergone ACL reconstruction. Knee Surg Sports Traumatol Arthrosc. 2006;14(8):778-788. PMID:16525796.

20. Gustavsson JP, Bergman H, Edman G, Ekselius L, von Knorring L, Linder J. Swedish universities Scales of Personality (SSP): construction, internal consistency and normative data. Acta Psychiatr Scand. 2000;102(3):217-225. PMID:11008858.

21. Hewitt PL, Flett GL. Perfectionism in the self and social contexts: conceptualization, assessment, and association with psychopathology. J Pers Soc Psychol. 1991;60(3):456-470. PMID:2027080.

22. Hoch MC, Farwell KE, Gaven SL, Weinhandl JT. Weight-Bearing Dorsiflexion Range of Motion and Landing Biomechanics in Individuals With Chronic Ankle Instability. J Athl Train. 2015;50(8):833-839. PMID: 26067428.

23. Irrgang JJ, Anderson AF, Boland AL, et al. Development and validation of the international knee documentation committee subjective knee form. Am J Sports Med. 2001;29(5):600-613. PMID: 11573919.

24. Irrgang JJ, Anderson AF, Boland AL, et al. Responsiveness of the International Knee Documentation Committee Subjective Knee Form. Am J Sports Med. 2006;34(10):1567-1573. PMID: 16870824.

25. Kaeding CC, Aros B, Pedroza A, et al. Allograft Versus Autograft Anterior Cruciate Ligament Reconstruction: Predictors of Failure From a MOON Prospective Longitudinal Cohort. Sports Health. 2011;3(1):73-81. PMID: 23015994.

26. Konor MM, Morton S, Eckerson JM, Grindstaff TL. Reliability of three measures of ankle dorsiflexion range of motion. Int J Sports Phys Ther. 2012;7(3):279-287. PMID: 22666642.

27. Kvist J, Kartus J, Karlsson J, Forssblad M. Results from the Swedish national anterior cruciate ligament register. Arthroscopy. 2014;30(7):803-810. PMID:24746404.

28. Kvist J, Österberg A, Gauffin H, Tagesson S, Webster K, Ardern C. Translation and measurement properties of the Swedish version of ACL-Return to Sports after Injury questionnaire. Scand J Med Sci Sports. 2013;23(5):568-575. PMID:22257241.

29. Logerstedt D, Di Stasi S, Grindem H, et al. Self-Reported Knee Function Can Identify Athletes Who Fail Return to Activity Criteria up to 1 Year After Anterior Cruciate 
Ligament Reconstruction: A Delaware-Oslo ACL Cohort Study. J Orthop Sports Phys Ther. 2014:1-27.

30. Losciale JM, Zdeb RM, Ledbetter L, Reiman MP, Sell TC. The Association Between Passing Return-to-Sport Criteria and Second Anterior Cruciate Ligament Injury Risk: A Systematic Review With Meta-Analysis. J Orthop Sports Phys Ther. 2018:1-52. PMID: 30501385

31. Mohtadi N. Development and validation of the quality of life outcome measure (questionnaire) for chronic anterior cruciate ligament deficiency. Am J Sports Med. 1998;26(3):350-359. PMID:9617395.

32. Moisen G.G. 2008. Classification and regression trees. In: Jorgensen, Sven Erik; Fath, Brian D., eds. Encyclopedia of Ecology, Volume 1. Oxford, U.K.: Elsevier. p.582-588.

33. Myer GD, Ford KR, Hewett TE. Tuck Jump Assessment for Reducing Anterior Cruciate Ligament Injury Risk. Athl Ther Today. 2008;13(5):39-44. PMID:19936042.

34. Myer GD, Ford KR, Hewett TE. New method to identify athletes at high risk of ACL injury using clinic-based measurements and freeware computer analysis. Br J Sports Med. 2011;45(4):238-244. PMID:21081640.

35. Myer GD, Ford KR, Khoury J, Succop P, Hewett TE. Clinical correlates to laboratory measures for use in non-contact anterior cruciate ligament injury risk prediction algorithm. Clin Biomech (Bristol, Avon). 2010;25(7):693-699. PMID:20554101.

36. Myer GD, Ford KR, Khoury J, Succop P, Hewett TE. Development and validation of a clinic-based prediction tool to identify female athletes at high risk for anterior cruciate ligament injury. Am J Sports Med. 2010;38(10):2025-2033. PMID:20595554.

37. Paterno MV, Huang B, Thomas S, Hewett TE, Schmitt LC. Clinical Factors That Predict a Second ACL Injury After ACL Reconstruction and Return to Sport: Preliminary Development of a Clinical Decision Algorithm. Orthop J Sports Med. 2017;5(12):2325967117745279. PMID: 29318172.

38. Paterno MV, Kiefer AW, Bonnette S, et al. Prospectively identified deficits in sagittal plane hip-ankle coordination in female athletes who sustain a second anterior cruciate ligament injury after anterior cruciate ligament reconstruction and return to sport. Clin Biomech (Bristol, Avon). 2015.

39. Paterno MV, Rauh MJ, Schmitt LC, Ford KR, Hewett TE. Incidence of contralateral and ipsilateral anterior cruciate ligament (ACL) injury after primary ACL reconstruction and return to sport. Clin J Sport Med. 2012;22(2):116-121. PMID:22343967.

40. Paterno MV, Schmitt LC, Ford KR, et al. Biomechanical measures during landing and postural stability predict second anterior cruciate ligament injury after anterior cruciate ligament reconstruction and return to sport. Am J Sports Med. 2010;38(10):1968-1978. PMID:20702858.

41. Piussi R, Beischer S, Thomeé R, Hamrin Senorski E. Hop tests and psychological PROs provide a demanding and clinician-friendly RTS assessment of patients after 
ACL reconstruction, a registry study. BMC Sports Sci Med Rehabil. 2020;12:32. PMID: 32426142.

42. Plisky PJ, Rauh MJ, Kaminski TW, Underwood FB. Star Excursion Balance Test as a predictor of lower extremity injury in high school basketball players. J Orthop Sports Phys Ther. 2006;36(12):911-919. PMID:17193868.

43. Roos EM, Roos HP, Lohmander LS, Ekdahl C, Beynnon BD. Knee Injury and Osteoarthritis Outcome Score (KOOS)--development of a self-administered outcome measure. J Orthop Sports Phys Ther. 1998;28(2):88-96. PMID: 9699158.

44. Slimani M, Bragazzi NL, Znazen H, Paravlic A, Azaiez F, Tod D. Psychosocial predictors and psychological prevention of soccer injuries: A systematic review and meta-analysis of the literature. Phys Ther Sport. 2018;32:293-300. PMID: 29776844.

45. Tan SH, Lau BP, Khin LW, Lingaraj K. The importance of patient sex in the outcomes of anterior cruciate ligament reconstructions: A systematic review and meta-analysis. Am J Sports Med. 2016;44(1):242-254. PMID: 25802119.

46. Waldén M, Hägglund M, Werner J, Ekstrand J. The epidemiology of anterior cruciate ligament injury in football (soccer): a review of the literature from a gender-related perspective. Knee Surg Sports Traumatol Arthrosc. 2011;19(1):3-10. PMID:20532868.

47. van Mechelen W, Hlobil H, Kemper HC. Incidence, severity, aetiology and prevention of sports injuries. A review of concepts. Sports Med. 1992;14(2):82-99. PMID: 1509229.

48. Wasserstein D, Khoshbin A, Dwyer T, et al. Risk factors for recurrent anterior cruciate ligament reconstruction: a population study in Ontario, Canada, with 5-year follow-up. Am J Sports Med. 2013;41(9):2099-2107. PMID: 23857886

49. Webster KE, Feller JA. Exploring the High Reinjury Rate in Younger Patients Undergoing Anterior Cruciate Ligament Reconstruction. Am J Sports Med. 2016;44(11):2827-2832. PMID: 27390346.

50. Webster KE, Feller JA, Lambros C. Development and preliminary validation of a scale to measure the psychological impact of returning to sport following anterior cruciate ligament reconstruction surgery. Phys Ther Sport. 2008;9(1):9-15. PMID: 19083699.

51. Webster KE, Feller JA, Leigh WB, Richmond AK. Younger patients are at increased risk for graft rupture and contralateral injury after anterior cruciate ligament reconstruction. Am J Sports Med. 2014;42(3):641-647. PMID: 24451111.

52. Webster KE, Hewett TE. Meta-analysis of meta-analyses of anterior cruciate ligament injury reduction training programs. J Orthop Res. 2018;36(10):2696-2708. PMID: 29737024.

53. Webster KE, Hewett TE. What is the Evidence for and Validity of Return-to-Sport Testing after Anterior Cruciate Ligament Reconstruction Surgery? A Systematic Review and Meta-Analysis. Sports Med. 2019;49(6):917-929. PMID: 30905035 
54. Wiggins AJ, Grandhi RK, Schneider DK, Stanfield D, Webster KE, Myer GD. Risk of secondary injury in younger athletes after anterior cruciate ligament reconstruction: A systematic review and meta-analysis. Am J Sports Med. 2016;44(7):1861-1876.

PMID: 26772611 
Supplementary Appendix. All factors collected at baseline and the 24 selected independent factors (bolded and numbered 1-24) with finally 19 included (KOOS and SEBT were removed) in the Classification and Regression Tree (CART) analysis.

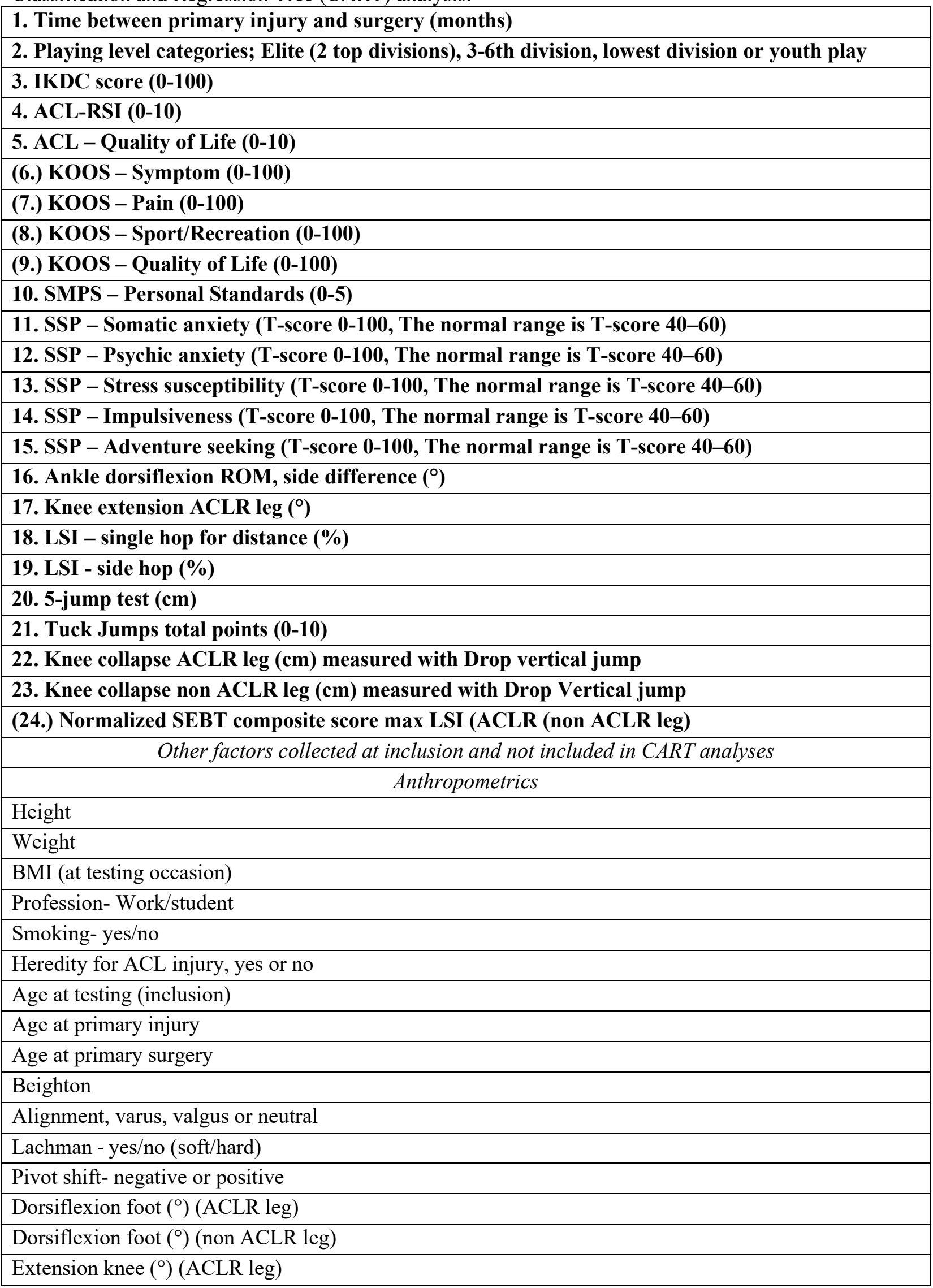




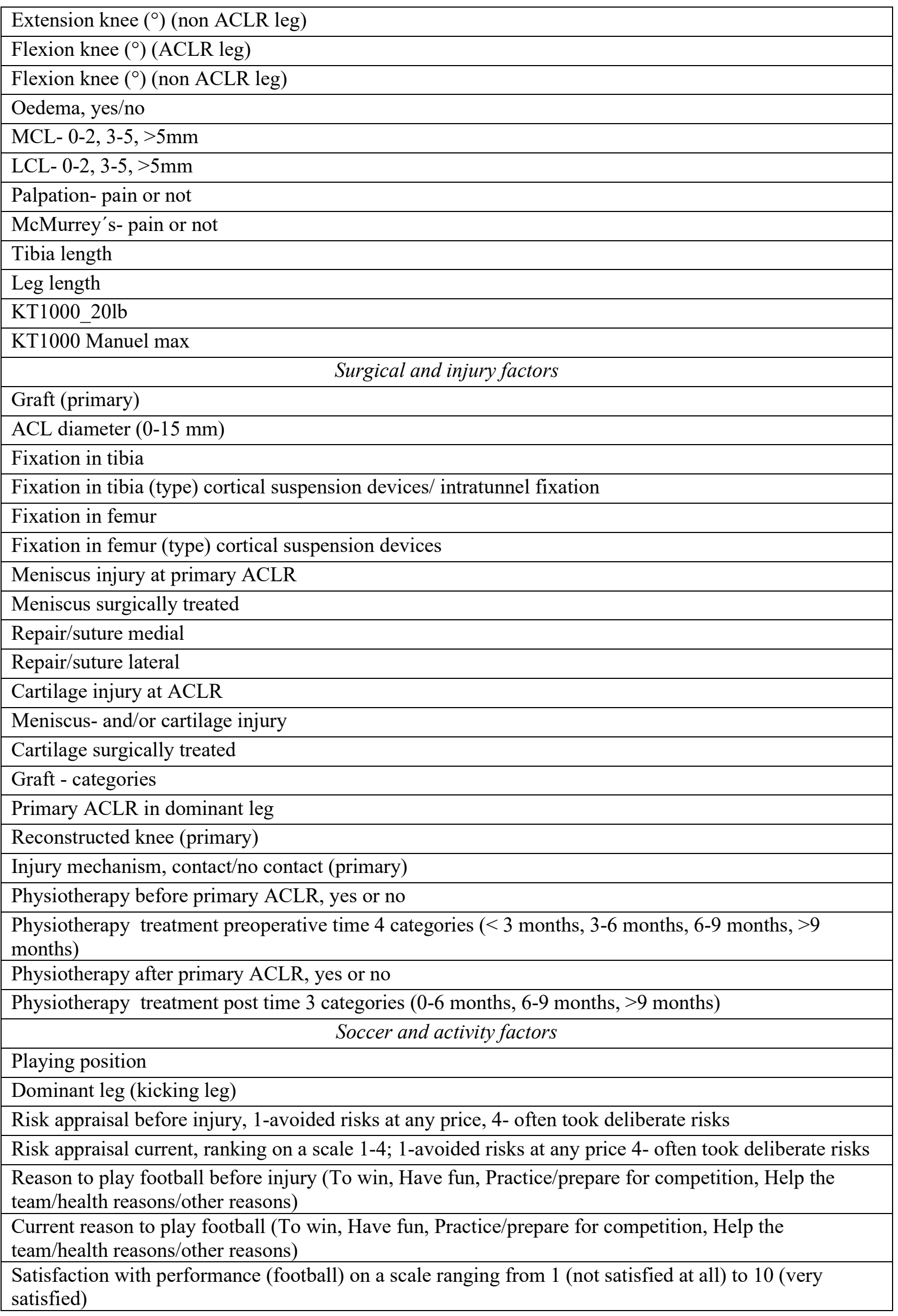




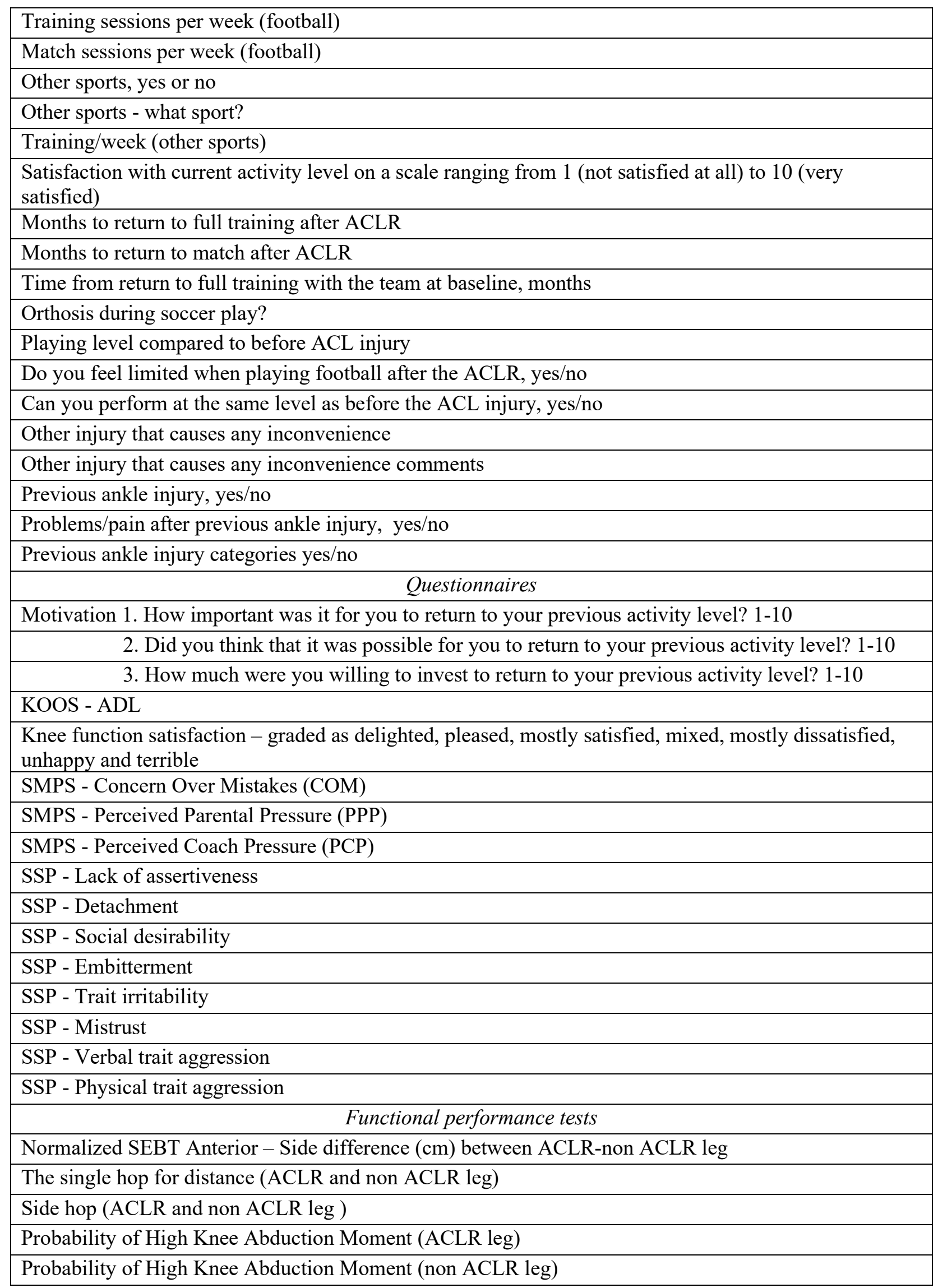

